\title{
Fibras, telas e hilos, vistos desde el arte
}

\section{Fibers, fabrics adn threads, seen from art}

\section{Julia Magdalena Caporal Gaytán ${ }^{a}$,Miguel Ángel Ledezma Campos ${ }^{b}$, Jesús Rodríguez Arévalo $^{c}$}

\begin{abstract}
:
Since the twentieth century, art has undergone a change, since it has not only conformed to the development of traditional classical techniques attributed to fine arts. In their search, the artists have transgressed the use of materials, formats and supports. Currently it is possible to find a large group of works that are the result of having retaken an ancestral discipline, we refer to the use of weaving and embroidery to create a new art, taking it to galleries, museums and open spaces to give it a meaning that goes beyond tradition. In this new type of practice, the sculptures or installations of Sheila Hicks, Francoise Grossen and Ewa Jarosznska, among others, stand out. These authors use different types of natural fibers to create this type of textile art, which, It is also known today as Fiber art. With the development of this research, it was observed that contemporary artists have followed in the footsteps of the first pioneering artists in the use of threads, fibers and fabrics in art, and with this they have achieved a greater openness so that textiles are no longer viewed solely as a minor art or craft.
\end{abstract}

.Haga clic o pulse aquí para escribir texto.

\section{Keywords:}

Embroidery, contemporary art, textile art.

\section{Resumen:}

A partir del siglo XX el arte ha tenido un cambio, ya que no sólo se ha conformado con el desarrollo de las técnicas clásicas tradicionales atribuidas a las bellas artes. En su búsqueda, las y los artistas, han transgredido el uso de los materiales, de los formatos y de los soportes. Actualmente es posible encontrar un numeroso grupo de obras que son el resultado de haber retomado una disciplina ancestral, nos referimos al uso del tejido y el bordado para crear un nuevo arte, llevándolo a las galerías, a los museos y a espacios abiertos para darle un sentido que va más allá de la tradición. En este nuevo tipo de prácticas destacan las esculturas o las instalaciones de Sheila Hicks, Francoise Grossen y Ewa Jarosznska, entre otros. Estos autores utilizan diferentes tipos de fibras naturales para crear este tipo de arte textil, el cual, también es conocido hoy en día como Fiber art. Con el desarrollo de la presente investigación, se observó que artistas contemporáneos han seguido los pasos de los primeros artistas precursores en el uso de hilos, fibras y telas en el arte, y con ello han logrado una mayor apertura para que los textiles ya no sean vistos únicamente como un arte menor o artesanía.

\section{Palabras Clave:}

Bordado, arte contemporáneo, arte textil.

\section{Introducción}

En este escrito podremos encontrar algunos de los diferentes usos que se le ha dado al textil en el arte a través del tiempo, y cómo se ha empezado a clasificar dependiendo de sus características, además se plantearán dos categorías para el arte textil: obras bidimensionales y obras tridimensionales.

A partir del siglo $\mathrm{XX}$ el arte ha tenido cambios significativos, algunos de ellos tienen que ver con el uso de nuevos materiales como es el caso de la utilización de fibras naturales. Con estos materiales, principalmente a

\footnotetext{
Autor de Correspondencia, Universidad Autónoma del Estado de Hidalgo, https://orcid.org/0000-0003-0618-5897, Email: julia_caporal5241@uaeh.edu.mx

b Universidad Autónoma del Estado de Hidalgo, https://orcid.org/0000-0002-2211-2244, Email: miguel_ledezma4913@uaeh.edu.mx c Universidad Autónoma del Estado de Hidalgo, https://orcid.org/0000-0003-1437-5156, Email: jesus_rodriguez4912@uaeh.edu.mx
} 
inicios de la segunda mitad del siglo XX, artistas de las neovanguardias crearon un nuevo tipo de esculturas blandas, ya que no se utilizaban los materiales duros, pesados y permanentes de la tradición de la escultura. En cuanto a la imagen bidimensional y material, ya no se usan sólo óleos o acrílicos sino que, por decirlo de algún modo, se pinta con hilos de colores o con pedazos de tela. También existen, en el medio de la fotografía, algunos artistas que las intervienen con hilos y bordado. En el grabado también encontramos piezas que, además de la impresión de la matriz sobre el papel, se crean otras formas y líneas con fibras, hilos y telas.

Laura Rodríguez Peinado (2003), menciona que, en la historia de la humanidad, se considera que el tejido es una de las técnicas más antiguas, ya que se dio el caso del descubrimiento de las primeras agujas en el periodo Paleolítico (20.000 años a.C). Se cree que estas simples herramientas fueron usadas para cocer pieles y confeccionar las primeras prendas de la historia. En la actualidad, generalmente se piensa que el oficio textil es sólo un arte menor o un arte de decoración, pero no es así, ya que, como nos comenta Leonis (2013), el arte textil es una forma de representar o plasmar una idea $y$, además, es una manera de comunicación entre individuos y grupos sociales. Esto es comprobable si observamos los tejidos de nuestros antepasados, los cuales presentan formas geométricas y otras formas simbólicas para representar deidades, cosas de la naturaleza e incluso historias 0 hechos. En diversos textiles, ya sea ornamentales o funcionales, tales como prendas de vestir, tapetes y gobelinos se representaron, y se siguen representando, imágenes del cosmos, de temas religiosos y místicos, entre otros. Cabe destacar que tradicionalmente la tarea de tejer y bordar era elaborada por mujeres, ya que en algunas culturas sólo ellas tenían asignada esta actividad (Yllades, 2015).

Abordar el estudio del bordado desde un enfoque artístico es una forma de estudiar las soluciones que el ser humano ha tenido para la conformación y mejora de su espacio íntimo a través de la confección de objetos e imágenes con hilos, telas y bordados entre otros (Blanca, 2014), pero también para la compresión de las cualidades estéticas del textil y su impacto sociocultural. Para ello es necesario hacer una revisión de los usos textiles en el arte, principalmente en el arte de los siglos $\mathrm{XX}$ y $\mathrm{XXI}$.

Esta investigación tiene como objetivo principal, comprender y clasificar las obras del arte textil actual a partir de sus cualidades estéticas y artísticas. Desde este enfoque, se observará el textil principalmente como obra de arte, pero sin dejar de lado, en algunos casos, su uso utilitario.
El presente artículo forma parte del inicio de esta amplia investigación, en donde se esbozará una posible ruta metodológica a partir de la división entre obras de arte bidimensionales y obras de arte tridimensionales para el análisis del arte textil o fiber art. Los resultados de esta investigación pueden tener un uso de consulta para los investigadores o creadores que les interese saber más del textil como obra de arte.

\section{Desarrollo}

A diferencia de otras épocas, actualmente el bordado y el tejido ya no son sólo una tarea de y para mujeres, ya que actualmente lo practican también algunos hombres. Hoy en día, los textiles ya no son encasillados, únicamente, en el campo de los oficios y las artesanías o el arte popular, ya que, como se ha reiterado a lo largo de estas líneas, se ha estado utilizando en el arte para poder transmitir ideas, generar imágenes y para realizar esculturas, ambientaciones o instalaciones en espacios públicos o privados.

De la Colina y Chichón Espino (2012) plantean una taxonomía del empleo del textil en el arte, agrupándolas en obras que tienen una utilización del textil del ámbito únicamente formal; otras en donde se utiliza como elemento para generación de colectivos y experiencias sociales y finalmente, plantea un tercer grupo de obras que no están directamente relacionadas con el contexto artístico.

Desde nuestra enfoque metodológico, es viable hacer un primer acercamiento hacia el uso de textiles en el arte desde las prácticas objetuales iniciadas en las vanguardias de principios del siglo $\mathrm{XX}$, particularmente con los readymade de Marcel Duchamp. En el arte objetual, los objetos cotidianos del entorno son descontextualizados para asignarles un significado y una asociación nuevos. Los autores trasladan uno o varios objetos, generalmente tomados de la cultura de masas y elaborados en serie, a una galería en donde pierden su contexto y su función original, resignificándose como una obra de arte a través del juego: objeto de arte y objeto de uso.

El arte objetual, a partir de los readymade, replanteó el problema de la técnica y la manufactura, cuestionando si la manufactura es un elemento indispensable para que algo pueda ser considerando arte. Para la segunda mitad del siglo $\mathrm{XX}$, en movimientos artísticos como el nuevo realismo, el neo dadaísmo y el arte conceptual, entre otros, ya no tuvo tanta importancia el hecho de tener un conocimiento manual práctico y técnico vinculado a las disciplinas de las bellas artes, tales como la pintura o la escultura. Tampoco era indispensable el proceso de factura manual, por el cual, 
las obras de arte tradicionalmente llegaban a tomar forma; sino que, ahora, con tan sólo tomar un objeto prefabricado y sacarlo de su contexto original, era posible generar una nueva obra, la cual, tenía como uno de sus objetivos principales, cuestionar el concepto tradicional de arte y, por lo tanto, el objeto comercial característico del arte tradicional, generalmente asociado a la belleza y la verdad.

A partir de la utilización de objetos prefabricados en el arte surgieron nuevos medios como el ensamblaje y la instalación. $Y$ es en este tipo de prácticas que podemos encontrar el uso, apropiación y reutilización de textiles en el arte. Un ejemplo de ello, es la utilización del nylon en el la escultura, en donde destaca el trabajo de Sarah Lucas, Ernesto Neto y María Ezcurra.

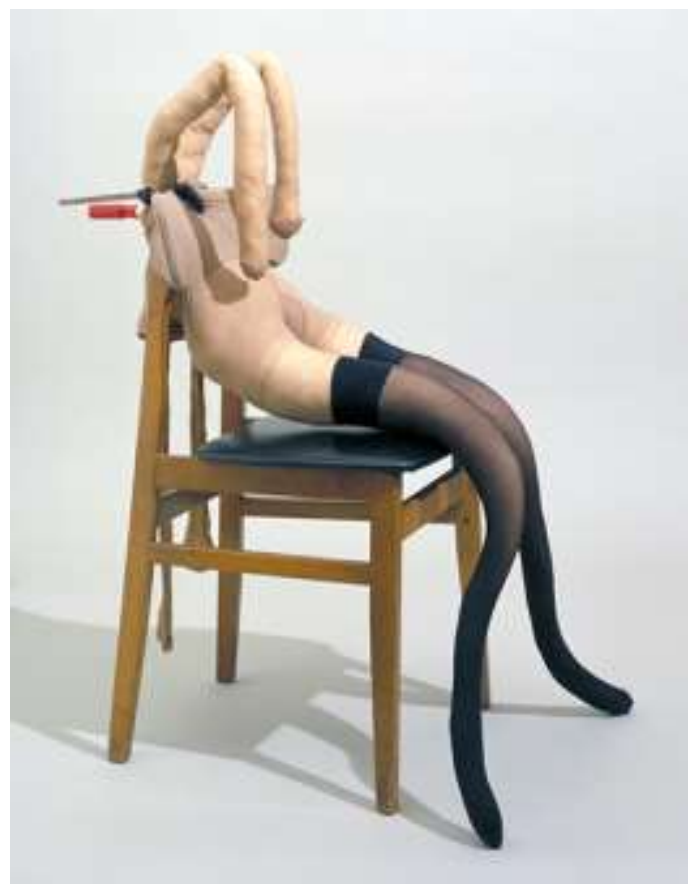

Figura 1. Sara Lucas, Pauline Bunny, 1998. Imagen tomada de https://www.tate.org.uk/art/artworks/lucaspauline-bunny-t07437

Una prenda de vestir confeccionada principalmente para el cuerpo femenino, es el material del que está elaborada la pieza Pauline Bunny de Sarah Lucas en 1997 (Fig. 1). Esta pieza está entre el readymade y la escultura, ya que a través del ordenamiento y la manipulación de objetos cotidianos, la autora da forma a una figura que evoca a un cuerpo femenino sentado sobre una silla de madera. Lucas rellenó con guata, material con el que se rellenan las amohadas, un par de juegos de pantimedias femeninas para dar forma a un cuerpo abyecto de mujer, las largas piernas rellenas en la parte superior, se doblan flácidamente evocando la forma de una orejas de conejo. La parte inferior está integrada por unas pantimedias color negro, las cuales se relacionan al estereotipo de la mujer sensual (Lucas, 1998).

El uso del textil aquí es simbólico, ya que Sarah Lucas elige cuidadosamente los objetos y colores con los que trabaja, particularmente las pantimendias. Estas prendas íntimas de vestir son transfiguradas para representar el cuerpo femenino, pero al mismo tiempo, lo lo deforman en una figura sexualizada y monstruosa.

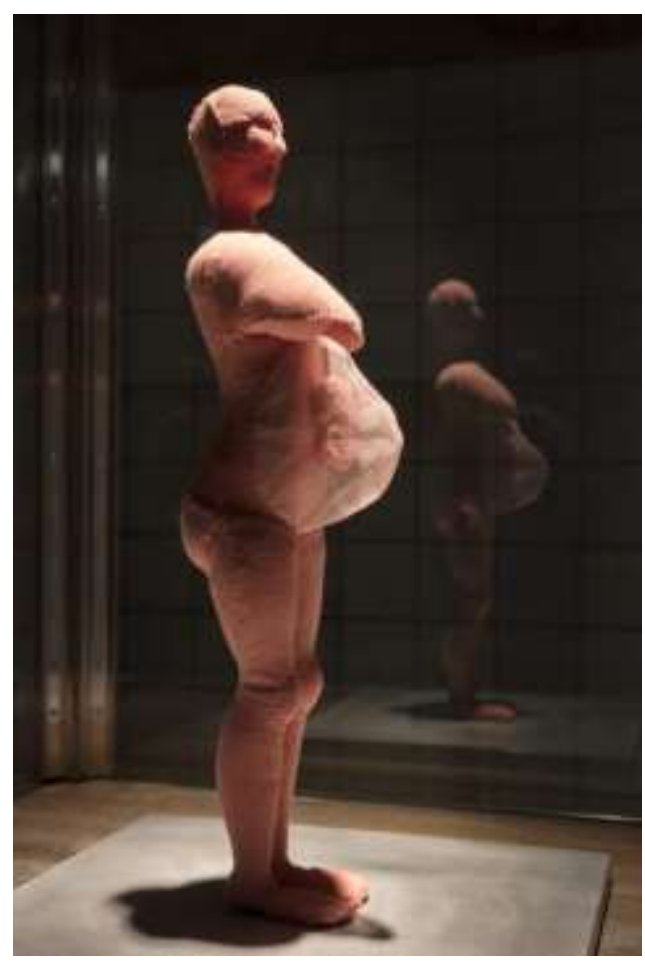

Figura 2. Escultura de tela y guata elaborada por Louise Bourgeois. Imagen tomada de

http://www.rotundamagazine.com/louise-bourgeoisschinkel-jerry-gorovoy-x-marieve-lafontaine/

Continuando con el desarrollo de un panorama del uso de los textiles en el arte. También tenemos un grupo de piezas escultóricas hechas con bordados o con la técnica del patchwork, es decir, la unión de trozos de tela con costuras. En este campo destacan algunas piezas de Louise Bourgeois, que realizó con estambre y tela para formar rostros y figuras humanas, similares a las tradicionales muñecas de trapo. Los cuerpos, generalmente femeninos, hechos de tela y en algunos casos con bordado, son la variante escultórica suave y flexible de sus esculturas en mármol o de sus conocida serie instalaciones llamada de Celdas. 
Las esculturas de tela de Bourgeois remiten a temas de la feminidad, la maternidad, la sexualidad, el amor y otros temas recurrentes en la obra de la autora relacionados con el existencialismo, tales como la angustia, la enfermedad y la muerte (Fig. 2).

Si se comparan las piezas de Bourgeois hechas en mármol con las que hizo con hilo y tela, se observa que las últimas tienen un impacto estético distinto en el espectador. Es posible que su cercanía con objetos con objetos de uso cotidiano e íntimo, tales como los muñecos de peluche, provoquen un enlace afectivo con el público. Formalmente también destaca la relación figurativa de los cuerpos femeninos de tela y guata con las antiguas figurillas de venus elaboradas en el periodo paleolítico.

Otro artista contemporáneo que trabaja con formas relacionadas con muñecos de peluche es Francoise Sablons, que a partir del tejido realiza sus esculturas de animales imaginarios. Así es como los artistas han retomado al tejido para poder hacer sus piezas y llevarlo al museo o la galería el recrea un espacio que va de lo imaginario a lo real. El acercamiento a nuevos materiales en el arte y la utilización de técnicas asignadas por la tradición a las artesanías, ampliaron el espectro de posibilidades de la producción artística. Desde entonces, la variedad de piezas que usan hilo, fibras y tejidos es muy amplia. En el arte actual es muy frecuente encontrarlas en bienales y exposiciones en museos y galerías.

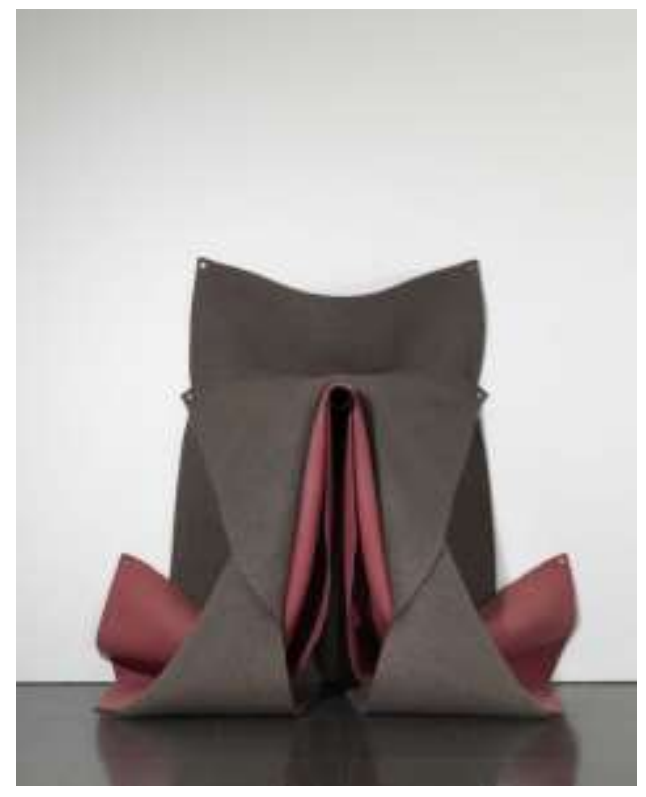

Figura 3. Robert Morris, House of Vetti II, 1983. Imagen tomada de https://www.macba.cat/es/arteartistas/artistas/morris-robert/house-vetti-ii
Durante el postminimalismo, en la segunda mitad del siglo XX, Robert Morris y Eva Hesse, también tuvieron un papel destacado en la utilización de este tipo de materiales en piezas escultóricas cuya forma era cambiante, a diferencia de la roca o el bronce. Las esculturas blandas de fieltro hechas por Morris en el resultado de sus reflexiones en artículos y ensayos como "Antiforma" y "Notes on sculpture" publicados en Artforum en 1968 y 1969 (Guasch, 2000). Centrando su atención en los materiales por encima de su manipulación formal, presentó en esta época unas esculturas hechas de fieltro colgadas sobre la pared o depositadas sobre el piso. Los lienzos de fieltro caían libremente tomando una forma que no había sido determinada previamente (Fig. 3).

En el caso de Hesse, la experimentación fue hecha con cordones entrelazados y suspendidos del techo o incorporados en algunas piezas escultóricas. Las obras Hesse son más orgánicas y sensuales que la mayoría del arte que se estaba produciendo en la misma época.

Las piezas de Hesse y Morris, al lado de otros artistas experimentales en la década de los años sesenta del siglo $\mathrm{XX}$, exploraron con la utilización de nuevos materiales, lo que dio pie a un grupo novedoso de esculturas suaves y blandas.

Si bien, los artistas antes mencionados son artistas de gran renombre a nivel internacional. Es otro grupo de artistas quienes podemos considerar realmente como precursores del arte textil o fiber art. A finales de la década de los años sesenta, se presentó en el Museo de Arte Moderno de Nueva York la exposición Wall Hangings, organizada por Milderd Constantine y Jack Lenor Larsen (Auther, 2010). En esta primera exposición no se tuvo tanta aceptación con la prensa y los críticos pero los artistas lograron una cosa muy importante: posesionarse de los diferentes materiales como las fibras naturales y los textiles para así generar un arte de vanguardia. En esta exposición de arte nos encontramos con autores como: Alice Adams, Sheila Hicks, Francoise Grossen, Ewa Jaroszynska y Lenore Tawney entre otros, los cuales ocuparon diversas fibras y tejidos naturales para realizar esculturas o piezas tridimensionales, las cual nos llevan a la transición de del textil tradicional a la escultura textil, y, por qué no, hasta la instalación.

A partir de esta muestra colectiva se usaron muchos términos para nombrar este tipo de arte, tales como formas tejidas, construcciones de fibra, nuevo tapiz y escultura textil, aunque el más utilizado, como ya se mencionó es fiber art. (Auther, 2010).

De acuerdo a lo expuesto hasta aquí, se ha observado que existe una gran diversidad de obras que 
usan fibras, tejidos y textiles en el arte contemporáneo. Por lo anterior, para hacer un planteamiento de análisis metodológico, se optará por ordenarlas a partir de dos grandes bloques, los cuales son:

1) Obras tridimensionales. Pueden ser esculturas 0 objetos, ambientaciones o instalaciones. Su contenido y forma va más allá del largo y ancho. Generalmente es una forma que se debe observar por todos sus lados (ancho, largo, alto, vista superior y vista inferior), si es posible.

2) Obras bidimensionales: Generalmente se incluye aquí la fotografía, la pintura y la gráfica. El arte bidimensional se extiende por dos dimensiones, es un plano que sólo tienen ancho y largo. En esta superficie se ordenan los diferentes elementos plásticos para generar una imagen, tales como la línea, el punto y el plano entre otros.

De acuerdo a la tipología anterior, es necesario distinguir que los ejemplos mencionados hasta aquí deberán ser ubicados en el bloque de las obras tridimensionales. En este panorama, se vislumbran otros subgrupos, por ejemplo, los artistas que usan textiles como readymade, como el caso de Sarah Lucas, de aquellos que no lo usan. También existen obras que son elaboradas a partir del tejido, y otras que usan y ensamblan telas previamente prefabricadas, ambos tipos de producción practicados por Louise Bourgueois.

También podremos clasificar obras que van colgadas al muro a manera de relieve, como es el caso de las obras de Robert Morris; esculturas exentas, es decir, que pueden ser observadas por todos sus lados mientras el espectador camina a su alrededor. Finalmente tendremos las obras de ambientación o instalación, en donde el espectador es engullido por el espacio de la obra, es literalmente rodeado.

En este campo de la instalación podemos citar como ejemplo la obra Annette Messager, quien también trabaja con telas, hilos y objetos textiles. En la pieza Articulés-desarticulés un conjunto de formas de tela rellenos, a manera de muñecos de peluche cuelgan por toda la galería e incluso, se acumulan sobre el suelo (Fig. 4). Al observar con detalle, el espectador se percata de que los objetos representan órganos del cuerpo como intestinos, estómagos y otros formas difíciles de reconocer. Conforme el artista avanza, se percata que esta rodeado por la representación de fragmentos de cuerpos de tela.

Con estas nuevas tendencias, que permiten jugar con diferentes materiales y retomar disciplinas que tienen su origen hace muchos años, el arte contemporáneo se refresca y permite que los artistas experimenten, exploren, e intervengan los nuevos tradicionales con hilos bordados y fibras, para así poder dar una nueva lectura al arte actual.

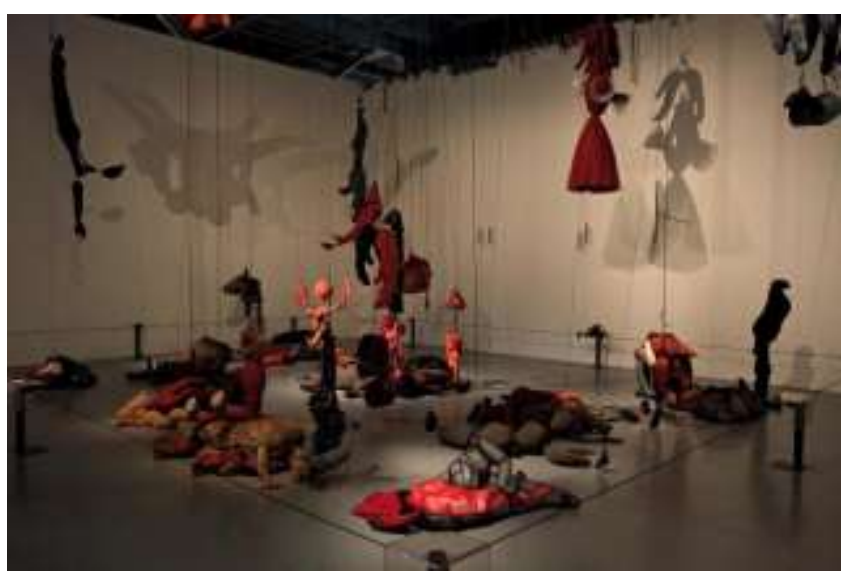

Figura 4. Annette Messager, Articulés-desarticulés, 2001-2002. Imagen tomada de

https://www.centrepompidou.fr/es/colecciones/artesplasticas

Otra artista que desarrolla instalaciones es Sarah Moli. Ella trabaja con el textil y sus piezas principales están realizadas con tejido con ganchillo, manejando el hilo de lana como materia prima. Las piezas que ella crea son muy personales y en ocasiones trabajo con mucho color sus formas son muy orgánicas y están hechas para sitio específico. Las formas geométricas y colores que utiliza son muy cercanas a tejido popular, aquel realizan artesanos para hacer objetos útiles como boinas, pulseras y adornos (Corral, 2015). Los tejidos de Moli se despliegan por varios meros a lo largo del piso, las paredes y el techo, acumulándose en montañas de formas abstractas y policromáticas. Generalmente son abstractas.

De acuerdo a lo anterior, se observa que existe una nueva corriente híbrida entre arte y textil, escultura e instalación que debe ser analizada a detalle en un texto más amplio.

Para las obras que usan hilos pero que sólo se extienden en una superficie bidimensional es más pertinente el uso del bordado con hilos de colores sobre una tela $u$ otro tipo de soporte, como puede ser el papel. Como ya se mencionó, el arte bidimensional se entiende por dos dimensiones sobre un plano, es decir ancho y largo, en donde se aplican diferentes elementos plásticos para la composición.

Un ejemplo de artista que hace piezas bidimensionales con bordado es la norteamericana Lara Blanchard, quien realiza grabados que posteriormente imprime sobre tela, los cuales son intervenidos con el 
bordado utilizando diferentes hilos y colores para darle texturas muy delicadas y sofisticadas a sus grabados los cuales regularmente son imágenes de rostros y formas de criaturas híbridas.

También existen artistas más conocidas en el arte internacional como Ghada Amer, la cual interviene algunas piezas de gráfica y pintura con hilos, bordando formas de mujeres. Los hilos pasan a formar parte de las pinturas, entrelazándose armónicamente con las pinceladas. Algunas otras obras, toda la imagen está construida a partir del bordado (Fig. 5).

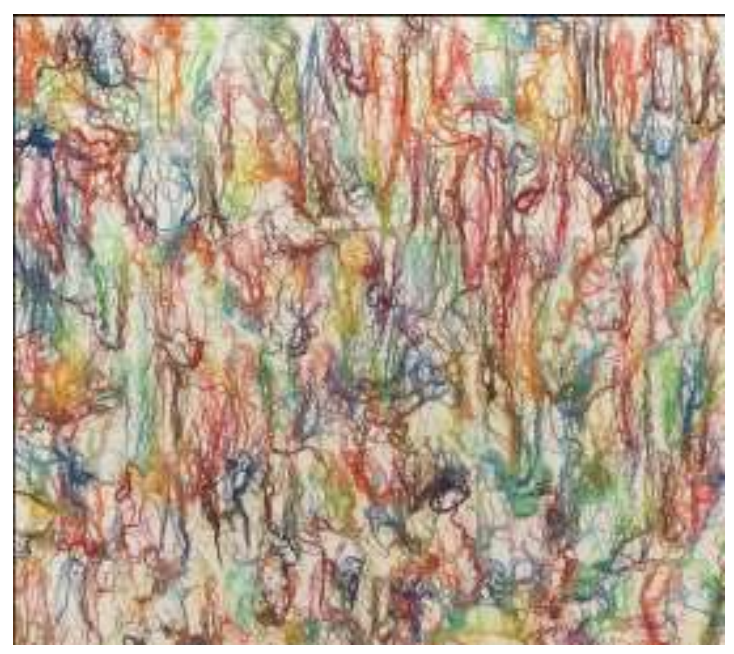

Figura 5. Ghada Amer, My Numpheas \#2, 2018. Imagen tomada de https://www.ghadaamer.com/paintings

Un antecedente directo de las piezas que hacen estas mujeres es, por supuesto, la elaboración de diseños textiles en la Bauhaus para fusionar arte y diseño en la vida cotidiana. También tenemos algunos artistas de la pintura matérica, como Alberto Burri y Manolo Millares, quienes utilizaron la tela como un elemento expresivo principal en sus obras. Sin embargo, también será necesario abordar este tipo de piezas bidimensionales y sus posibles hibridaciones con medios tradicionales en un momento posterior que permita analizar estas obras con profundidad.

Como se ha desarrollado a lo largo de estas líneas, la experimentación con hilos, telas y fibras ha llevado a diferentes artistas a abordar temas diversos y crear nuevas formas de arte, bidimensionales 0 tridimensionales, las cuales han tenido buena aceptación en el público. Esto ha generado que las galerías abran sus puertas a este nuevo concepto de arte textil a través de piezas simples 0 de grandes instalaciones (Sierzputowski, Kate, 2019). Un ejemplo de los múltiples catálogos que documentan este tipo de exposiciones y obras, es Fibras 09 (Tobon, et. al., 2008), publicado por Caja Madrid. En este se pueden distinguir constantes formales que enlazan las obras de artistas españolas recientes con aquellos artistas pioneros del fiber art a finales de los años sesenta del siglo $\mathrm{XX}$, tales como Sheila Hicks y Eva Hesse.

Cabe destacar que en México también tenemos varios artistas, principalmente mujeres, que trabajan con textil en el arte, tales como Mónica Castillo y Tania Candiani, entre otras. En la búsqueda de la recopilación de la información para esta investigación nos dimos a la tarea visitar en la ciudad de Oaxaca, México, el Museo textil, el cual se especializa en las relaciones entre el textil como artesanía y sus posibilidades artísticas. El museo presenta regularmente exposiciones con trabajos de artistas contemporáneos cuya obra está vinculada con el textil. El contexto local de arte textil amplía el horizonte hacia la investigación acerca de las relaciones entre este tipo de disciplinas tradicionales como el bordado y el tejido con otras piezas de arte y tecnología que, incluso, utilizan tecnología, como el el caso de la artista mexicana Amor Muñoz, quien en los últimos años ha trabajado con bordados interactivos, como el proyecto Maquila Región 4.

Como se puede observar, el panorama del arte textil en el arte contemporáneo es amplio y ha trazado nuevas rutas en la producción y en la interpretación del arte.

\section{Conclusiones}

Esta investigación nos llevó, en una primera parte, a reconocer que en el arte contemporáneo, de la segunda mitad del siglo $X X$ a la fecha, existe el uso de nuevos materiales aparentemente, ya que no son nuevos porque ya eran utilizados en otro campo, con otro sentido y para otro fin plástico, generalmente denominado como artes menores o artesanías. Con esta apertura hacia la utilización de fibras, hilos y tejidos, algunos artistas visuales se han desempeñado libremente en su producción artística con propuestas que abordan temáticas o problemáticas actuales a través de una amplitud de nuevas formas visuales.

Este primer acercamiento nos permitió partir de la división en dos grandes bloques de obras de acuerdo a sus características bidimensionales o tridimensionales, lo que dio apertura para distinguir nuevos subgrupos, tales como: obras que usan objetos fabricados por personas diferentes al autor, como readymade, y obras elaboradas por el autor en el arte tridimensional. En arte tridimensional también se distinguieron dos tendencias notables: obras tejidas y obras construidas con las unión de trozos de telas a través de hilos. En las obras bidimensionales se observaron piezas híbridas entre bordado y pintura, gráfica o fotografía y obras puras, construidas únicamente con bordados sobre tela o papel. 
Se concluyó que con estos materiales y técnicas el artista puede generar otros tipos de obra de arte y no encasillarse en los medios tradicionales como la pintura, la escultura o el dibujo.

De los resultados obtenidos aquí y de la recopilación de textos e imágenes nos daremos a la tarea, en artículos posteriores, de analizar a profundidad esta nueva tendencia dentro del arte, a partir de las tipologías construidas aquí, para comprender el trabajo de artistas contemporáneos, nacionales y extranjeros, que presentan sus trabajos en galerías o museos y que producen obras hechas con fibras, telas e hilos.

\section{Referencias}

[1] Angulo, A., \& Martìnez, M. M. (2016). El mensaje esta en el tejido. México: Futura Textos.

[2] Blanca, R. M. (2014). El bordado en lo cotidiano y en el arte contemporáneo. Feminismo, 2(3), 1-13. Obtenido de www.feminismos.neim.ufba.br

[3] Bondía Fernández, C. (2014). Artes textiles en el 2012. Nuevas tendencias en el arte textil contemporáneo preservación , material y conceptual, Museo Reyna Sofia, 254.

[4] Corral, R. (2015). Batik- arte textil milenario. Arte y sociedad. Revista de Investigación (8), 1-9.

[5] De la Colina Tejada, L., \& Chinchón Espino, A. (2012). El empleo del textil en el arte: aproximaciones a una taxonmía. Espacio, Tiempo y Forma. Serie V, T.4, 179-194. Madrid: Universidad Nacional de Educación a Distancia.

[6] Elderton, L., \& Morrill, R. (2019). Vitamina T, Threads \& Textiles. Nueva York: Phaidon.

[7] Guasch, A. (2000). El arte ultimo del siglo XX. Madrid: Alianza Forma.

[8] Heidegger, M. (1992). El origen de la obra de Arte en Arte y Poesia. FCE.

[9] Leonis, D. (2013). La producción Textil como actividad doméstica de los cazadores-recolectores prehispanicos en la región Pampeana, Arg. Intersecciones de Antropología, 16(1), 131144. Obtenido de http://www.scielo.org.ar/scielo.php?script=sci_arttext\&pid=S1 850-373X2015000100008

[10] Rodríguez Peinado, L. (2003). El textil en la antigüedad y la Alta Edad Media. Madrid: Facultad

[11] Sierzputowski, Kate. (14 de Enero de 2019). Colossal. Obtenido de Materiales de alfombra Deadstock Transformados en un jardiín de coral inmersivo por Vanessa Barragao: https://www.thisiscolossal.com/2019/01/coral-garden-byvanessa-barragao/

[12] Staugaitis, L. (7 de Junio de 2019). Colossal. Obtenido de Las instalaciones texturales de Shoplifter sumergen a los visitantes en las cuevas de neón: https://www.thisiscolosal.com/2019/06/shoplifter/

[13] Simón, M. F. (2008). Fibras 09. Arte textil contemporáneo. Madrid: Caja Madrid.

[14] Tobon, P, et. (2001). Del arte objetual al arte de concepto,Epiologo sobre la sensibilidad posmoderna. Madrid: Akal.

[15] Yllades, M. E. (2015). El textil: del mito del origen a la era multimedia. El textil: del mito del origen a la era multimedia, 371. Valencia, España: Universidad Politécnica de Valencia. Recuperado el 8 de junio de 2017, de https/riunet.upv.es/bitstream/handle/10251/57488/YLLADES $\% 20-\% 20$ El $\% 20$ textil $\% 34$ 